\title{
CONSIDERAÇÕES SOBRE HISTORIOGRAFIA E NARRATIVAA PARTIR DA LEITURA DE PEIXE GRANDE
}

\section{CONSIDERATIONS ABOUT HISTORIOGRAPHY AND THE NARRATIVE OF PEIXE GRANDE READING}

DOI: http://dx.doi.org/10.15448/2178-3748.2015.1.17880

\author{
André Pereira Leme Lopes \\ Professor da Universidade de Brasília - UNB \\ E-mail: a.lemelopes@gmail.com
}

\begin{abstract}
RESUMO: Durante milênios, as histórias foram entendidas como representações (mímesis) do mundo. Neste texto, procuro fazer uma breve releitura desses dois conceitos (mímesis e representação) em alguns textos de teoria literária, psicanálise e filosofia. A partir do filme Peixe grande, dirigido por Tim Burton em 2003, que retrata a busca de um filho por dados da vida de seu pai, traço um paralelo entre a procura do filme e a atividade do historiador. Entretanto, no romance homônimo publicado pelo americano Daniel Wallace em 1998 e no métier d'historien, tudo que ambos os 'pesquisadores' encontram são histórias. Argumento, portanto, que tratar a historiografia como uma narrativa não limita nem constrange a possibilidade da existência de uma verdade histórica. Ao contrário, entendo as narrativas - e a historiografia - não como mímesis, reflexo, representação ou imitação de uma realidade social pré-existente, mas sim como definidoras e criadoras de realidades próprias.
\end{abstract}

PALAVRAS-CHAVE: Mímesis. Representação. Verdade.

\begin{abstract}
For millennia, narratives where understood as representations (mimesis) of the world. Here, I do a quick analysis of these two ideas in some literary theory, psychoanalysis, and philosophy works. After watching the movie Big fish, directed by Tim Burton in 2003, which depicts the search of a son for his father's life history, I equate his investigation with the historian's occupation. But in the homonymous novel published by the American writer Daniel Wallace in 1998, or in the métier d'historien, everything they find is a story. I argue then that to realize historiography as a narrative does not makes History untruthful. Instead, I claim that stories aren't mimesis, a reproduction, a representation, or an imitation of a pre-existing social reality, but creators of their own realities.
\end{abstract}

KEYWORDS: Mimesis. Representation. Truth.

\section{O Filme e o Historiador}

O tema deste texto é a relação entre realidade, linguagem, verdade e história - tanto no seu sentido de narrativa, a 'estória', para usar um barbarismo cunhado por Guimarães Rosa, quanto no sentido de História, com ' $h$ ' maiúsculo, disciplina acadêmica. Trata-se de um tema que me acompanha desde minha graduação e que voltou à minha mente há alguns anos quando assisti ao filme Peixe grande e suas histórias maravilhosas (AUGUST; BURTON, 2003), que conta a história da relação entre um pai e seu filho, Edward e William Bloom.

Oficina do Historiador, Porto Alegre, EDIPUCRS, v. 8, n. 1, jan./jun. 2015, p. 99-116. 
O conflito central do filme nasce do fato de que Edward, um vendedor ambulante que passou boa parte da vida viajando, sempre contou as mais variadas - e fantásticas - histórias sobre sua biografia e isso gerou uma enorme desconfiança em seu filho que acredita não conhecer o pai. Irritado com o que vê como mentiras, William passa anos sem falar com ele até que, com Edward em seu leito de morte, ele tenta se aproximar para descobrir, finalmente, quem realmente é seu pai, mas não consegue ouvir o que deseja:

WILL - Eu não tenho ideia de quem você é porque você nunca me contou um único fato. EDWARD - Eu te contei uns mil fatos. É tudo o que eu faço, Will. Conto histórias.

WILL - Você conta mentiras, pai. Você conta mentiras divertidas. Histórias [stories] são o que você conta para uma criancinha dormir. Não mitologias elaboradas que você mantém quando seu filho tem dez e quinze e vinte e trinta anos. E o fato é: eu acreditei em você. Eu acreditei nas suas histórias por muito mais tempo do que deveria.

...

EDWARD - O que você quer, Will? Quem você quer que eu seja?

WILL - Você mesmo. Bom, mau, qualquer coisa. Apenas mostre-me quem você é uma vez.

EDWARD - Eu não tenho sido nada a não ser eu mesmo desde o dia em que nasci. E se você não consegue ver isso, a falha é sua e não minha.

(AUGUST, 2004, cena 118, p. 82-83)

O que William deseja ouvir é algo tradicionalmente caro à História: o que chamamos de 'verdade factual' (cf. WILSON, 2008, §4s). Ele quer saber 'o que realmente aconteceu' na vida de seu pai para - quem sabe? - descobrir quem foi Edward Bloom. Por meio do conhecimento dos fatos da vida do pai, William pretende alcançar a verdade sobre aquela vida que ele não conhece: "eu diria que tive saudades de você - digo - se soubesse do que ter saudades" (WALLACE, 1998, p. 21; 2008, p. 28). Trata-se de uma situação comparável àquela do historiador: desejamos saber algo sobre o passado e o senso comum nos diz que conhecer 'os fatos', 'o que se passou', irá nos deixar mais próximos desse conhecimento que tanto ambicionamos.

William Bloom, portanto, age como uma espécie de historiador. Ele investiga a vida de seu pai e deseja saber a verdade sobre sua vida. É isso que ele demanda o tempo todo: a verdade, uma verdade factual, tradicional. Seu pai, no entanto,lhe respondeu apenas com histórias, com narrativas. De maneira bastante semelhante, o historiador deseja conhecer o passado; e tudo o que resta são histórias, narrativas. O passado não existe mais...

Os historiadores sempre foram fascinados pelo 'real'. Desde a Antiguidade clássica, ao menos, escreveram sobre eventos, pessoas, atitudes, comportamentos, ações e ideias baseando-se na ancoragem desses fenômenos na realidade por meio da observação.

Oficina do Historiador, Porto Alegre, EDIPUCRS, v. 8, n. 1, jan./jun. 2015, p. 99-116. 
Posteriormente, os documentos passaram a garantir a factualidade de seus objetos e, portanto, os historiadores concentraram suas discussões na crítica e na análise desses portais que davam acesso aos mundos do passado.

Durante o século XX, no entanto, pesquisas na área da filosofia da linguagem e da teoria da literatura, entre outras, apontaram um intruso nesse mundo perfeito da análise histórica da realidade: a linguagem não era neutra e o uso que os historiadores faziam dela interferia em seus objetos, seus procedimentos e, portanto, em toda uma série de questões que eram pressupostos do método histórico: "os historiadores estavam tão seduzidos pelo passado, [...] que esqueceram que estavam escrevendo textos, lendo textos, criando textos, processos que têm lógicas próprias, que requerem atenção a suas lógicas internas” (POSTER, 2009, p. 40).

Embora na historiografia tais questionamentos sejam comumente identificados com a marcante obra de Hayden White, Metahistory: the historical imagination in 19th-century Europe (1973), eles podem ser traçados até textos anteriores, como 'O discurso da história' (1967) e 'O efeito de real' (1968), do teórico da literatura francês Roland Barthes, ou Analytical philosophy of history (1965), do filósofo americano Arthur C. Danto. O primeiro artigo sobre o problema da narrativa histórica publicado na prestigiosa revista History \& theory, por exemplo, data de 1962 ('Narrative sentences', do supracitado Danto) e,desde então, apenas nessa revista foram publicados mais de setenta artigos sobre o tema, dez apenas no ano de 1987. Tal questão, no entanto, ultrapassa amplamente o campo historiográfico.

Como todo 'movimento' intelectual, é bastante difícil identificar uma 'origem' para esse desenvolvimento linguístico do pensamento, especialmente quando se trata de uma preocupação difusa como essa, mas a obra organizada por Richard Rorty, The linguistic turn: essays in philosophical method (1967), merece destaque por ter popularizado o nome de 'virada linguística', que, segundo o editor, se deve ao filósofo austríaco Gustav Bergmann (1906-1987). O alemão Gottlob Frege (1848-1925), o britânico Bertrand Russell (1872-1970), o austríaco Ludwig Wittgenstein (1889-1951), o alemão Rudolf Carnap (1891-1970) e o polímata alemão Walter Benjamin (1892-1940) também estão entre os primeiros filósofos a se voltarem para a investigação da linguagem.

Oficina do Historiador, Porto Alegre, EDIPUCRS, v. 8, n. 1, jan./jun. 2015, p. 99-116. 


\section{Histórias do Passado}

Não apenas a Guerra do Peloponeso de Tucídides, crônicas medievais ou a obra de Leopold Ranke são histórias do passado. Documentos pessoais, cartas, mementos, tudo isso são histórias que o passado nos conta. Mesmo uma certidão de nascimento ou um contrato de trabalho, documentos teoricamente neutros e impessoais, podem ser lidos como narrativas: tal pessoa nasceu no dia tal em tal lugar; fulano começou a trabalhar para sicrano (ou para a empresa X) no dia tal ganhando um salário de tantos dinheiros por unidade de tempo...

Neste momento seria conveniente discutir do que estamos falando quando usamos a palavra 'narrativa'. Embora uma definição formal do termo esteja longe do objetivo deste texto, me apropriarei aqui das oito “condições" listadas por Marie-Laure Ryan (2007, p. 28ss). Segundo a autora suíça, não se trata de uma lista binária, ou seja, de uma série de propriedades que um texto deve ou não possuir para ser considerado uma narrativa, mas da ideia da narrativa como um conjunto difuso que permite diferentes graus de pertencimento. Assim, as condições listadas pela autora são retiradas de casos exemplares que são tradicionalmente reconhecidos como narrativas e outros textos podem ser aproximados destes conforme possuam três ou mais condições.

Os exemplos aqui citados correspondem às condições de: (1) ocorrerem em um mundo habitado por indivíduos; (2) estarem situadas no tempo e passarem por transformações; (3) essas transformações serem causadas por eventos não-repetitivos; e (7) a ocorrência de pelo menos alguns dos eventos serem fatos no mundo narrativo. É interessante ressaltar, ainda, que as condições observadas correspondem completamente ao que Ryan chama de dimensões "espacial" (1) e "temporal" (2) e (3), tocando levemente a dimensão "formal e pragmática" (7) e ignorando completamente a dimensão "mental". ${ }^{1}$ De fato, os documentos de arquivo não pretendem mergulhar no universo mental dos indivíduos, mas apenas situá-los no espaçotempo e responder a uma necessidade protocolar. Assim, mesmo que não preencham todas as oito condições para serem consideradas 'narrativas completas', creio que se pode afirmar que diversos documentos chamados pela historiografia 'de arquivo' são narrativos de mais de um ponto de vista.

\footnotetext{
${ }^{1}$ Pode-se argumentar que um contrato de trabalho, por exemplo, cumpre a condição cinco, "algumas das ações dos indivíduos devem ser intencionais", pertencente à dimensão mental, mas certamente isso não pode ser dito de todos os documentos.
}

Oficina do Historiador, Porto Alegre, EDIPUCRS, v. 8, n. 1, jan./jun. 2015, p. 99-116. 
Documentos de arquivo, no entanto, por mais importantes que sejam, não constituem a totalidade das fontes históricas ou dos vestígios do passado. Não podemos nos esquecer dos monumentos arqueológicos, os ditos 'vestígios materiais'. Inscrições tumulares ou comemorativas, edificações, o conteúdo de túmulos, objetos de arte e outros restos físicos também são importantes fontes para o historiador. E são, usualmente, traduzidos em textos para que melhor os possamos compreender. Embora os primeiros possam ser facilmente identificados com histórias, normalmente, esses textos tomam o formato de uma descrição, a qual, por seu caráter estático, é tradicionalmente situada no campo oposto ao da narrativa.Não obstante, é possível imaginar histórias a partir dessas imagens: os restos de um naufrágio trazem à mente a tripulação da nau e toda a tragédia humana que se sucedeu; a descrição dos ferimentos em um corpo evoca a narrativa de sua morte;o traçado das ruas de uma cidade toma a forma de um passeio por elas - é como se o autor do documento estivesse caminhando pelas vias e contando-nos o que viu.

Dizer que todo documento pode ser lido como um texto narrativo não parece acarretar, em princípio, nenhuma consequência perniciosa para as noções tradicionais de História. De fato, parece óbvio afirmar que nenhuma fonte é o passado; elas apenas nos contam algo sobre o passado. Em uma conclusão similar, Freud reconhece como um fato elementar que aquilo que se chama comumente de 'sonho' nunca é o próprio sonho como ele foi sonhado, apenas a narrativa de um sonho, na qual o Eu já introduziu uma ordem racional que não havia na experiência onírica original (cf. RICCEUR, 2008, p. 219). Hans-Robert Jauss afirmou (1987, p. 118) há mais de vinte anos que a reflexão hermenêutica "percebeu que os res factce não são um dado primário, mas um resultado", um resultado de operações realizadas pela imaginação e pela narrativa: “a estetização ou, melhor, a 'ficcionalização' está operando continuamente na experiência histórica". Com efeito, esse tipo de operação narrativa fica bem clara quando observamos a declaração de uma testemunha:

A declaração explícita da testemunha [...] é bem expressiva: "eu estava lá". O imperfeito gramatical marca o tempo, ao passo que o advérbio marca o espaço. É em conjunto que o aqui e o lá do espaço vivido da percepção e da ação e o antes do tempo vivido da memória se reencontram enquadrados em um sistema de lugares e datas do qual é eliminada a referência ao aqui e ao agora absoluto da experiência viva. (RICCEUR, 2007, p. 156)

Ou seja, o espaço e o tempo são ressignificados no testemunho da experiência. O que a testemunha conta nunca é o acontecimento lembrado ou, mesmo, a experiência desse

Oficina do Historiador, Porto Alegre, EDIPUCRS, v. 8, n. 1, jan./jun. 2015, p. 99-116. 
episódio, e sim uma versão narrativa ressignificada por seu Eu, suas emoções, suas necessidades, suas pulsões, seus prós e contras, suas reações ao evento, suas experiências posteriores, etc.

\section{Mímesis e Realidade}

Durante séculos, a tradição interpretativa do Ocidente associou essa operação narrativa ao conceito de mímesis, normalmente traduzido por 'imitação' ou 'representação'. O que contamos sobre nossas experiências são mímesis dessas experiências. Tal interpretação tem origem nas fundadoras obras dos filósofos gregos Platão e Aristóteles. ${ }^{2}$ Em ambos, a operação mimética "supõe um ato de adequação ou correspondência entre a imagem produzida e algo anterior - em Platão, anterior e superior - que a guia" (COSTA LIMA, 2000, p. 34).

A divergência entre ambos se dá na valoração dada ao ato poético resultante da mímesis. Em Platão, a poesia é rejeitada epistemologicamente como uma imitação de segunda ordem (a poesia mimetiza a natureza, que, por sua vez, já é uma mímesis do mundo das ideias, o único mundo'real'). Em consequência dessa rejeição, Platão desvaloriza a poesia uma segunda vez, pedagogicamente, pois não possuindo conhecimentos verdadeiros, ela não os pode transmitir e, portanto, não pode educar os cidadãos. Aristóteles, por sua vez, considera que a poesia, ao narrar 'aquilo que poderia ter acontecido', demonstrava a universalidade das ações da humanidade. Assim, ao revelar as regularidades da experiência humana, a poesia podia se tornar uma ferramenta de conhecimento filosófico: "o universal é precioso porque revela a causa" (Analíticos posteriores I, 88 a 5).

Platão e Aristóteles também divergem quanto a relação da mímesis com a narrativa (diégesis). Segundo Platão, "tudo quanto dizem os prosadores e poetas" "é uma narrativa de acontecimentos passados, presentes ou futuros" e eles "a executam por meio de simples narrativa, por meio de mímesis ou por meio de ambas" (República III, 392d). Já para o filósofo de Estagira, a mímesis e não mais a narrativa ocupa o centro do palco; tudo quanto fazem prosadores, poetas e também músicos, pintores, escultores, atores, etc., é mímesis. De todo modo, ambos os filósofos reconhecem três formas de contar uma ação: a narrativa direta

2 Existem 'origens' pré-socráticas para o conceito de mímesis, mas a tradição Ocidental, normalmente, parte diretamente da República platônica e da Poética aristotélica. Ver TATARKIEWICZ, 1987, p. 301s.

Oficina do Historiador, Porto Alegre, EDIPUCRS, v. 8, n. 1, jan./jun. 2015, p. 99-116. 
(ou a mímesis narrativa), quando o poeta diz o que seus personagens estão fazendo; a narrativa mimética (ou a mímesis propriamente dita), quando o poeta compõe na forma de diálogos entre personagens; e um terceiro modo que é a mistura dos dois primeiros (ver BRANDÃO, 1996, p. 25-29).

De qualquer modo, a tradição ocidental, especialmente a partir do Renascimento, retomou as ideias de Aristóteles e transformou a mímesis na teoria fundamental do belo (ver TATARKIEWICZ, 1987, p. 305-310). Assim, se cada palavra pronunciada deve ter um referente exterior que lhe dê sentido (cf. Aristóteles, Metafísica, IV, 4, 1006a 11-15), muitos historiadores buscaram - e encontraram! - a 'realidade' que teria dado origem a importantes obras de nossa cultura, desde, por exemplo, os 'verdadeiros' rei Arthur e Robin Hood até o ‘exato' céu estrelado pintado por Van Gogh em 1889 (cf. DOLEŽEL, 1988, p. 475-476).Da mesma forma, ao final do filme Peixe Grande, William Bloom tranquiliza-se descobrindo os 'verdadeiros' personagens das histórias de seu pai.

Ao longo da película, William já vinha descobrindo algumas pistas de que as histórias de seu pai não eram tão impossíveis quanto ele acreditava inicialmente e, após a morte de Edward, William surpreende-se ao encontrar no enterro vários dos personagens da fantástica biografia paterna percebendo, por fim, que aquelas histórias eram apenas um exagero da verdade. Em uma de suas conversas enquanto seu pai definha, este lhe diz que a verdade está no fato de que ele é um contador de histórias e, por fim, William acaba por aceitar isso. Em uma das últimas cenas do filme, Edward, no hospital, pede a seu filho que lhe conte a história de sua própria morte e ele conta uma história prodigiosa, na qual seu pai se transforma em um peixe e se torna uma lenda entre os habitantes locais. Por fim, o próprio William continua a tradição familiar, contando as histórias de seu pai a seu próprio filho.

Se o filme Peixe grande nos presenteia com um final epistemologicamente feliz, que reconcilia 'verdade factual' e 'verdade narrativa', em que o investigador tem a possibilidade de descobrir que todas as histórias que ele ouviu eram 'realmente' verdade, tal não acontece no mundo do historiador. Em nossa área, não conseguiríamos jamais saber se nossa tese sobre o 'verdadeiro' rei Arthur ou o 'verdadeiro' Robin Hood está correta, pois eles não irão se levantar dos livros para nos cumprimentar ou corrigir.

E, se essas associações já são questões, no mínimo, problemáticas, a impossibilidade de encontrar referenciais 'reais' para todas as instâncias da ficção (quem foram, 'na vida real', Cândido, Tristram Shandy, Brás Cubas ou o Dr. Frankenstein?) levou a crítica mimética a um desvio, segundo o qual os particulares da escrita representavam reais 'universais' (cf.

Oficina do Historiador, Porto Alegre, EDIPUCRS, v. 8, n. 1, jan./jun. 2015, p. 99-116. 
DOLEŽEL, 1988, p. 477). Um exemplo típico dessa aproximação é a obra de Eric Auerbach, Mimesis (1946), na qual ele argumenta, por exemplo, que Dom Quixote e Sancho Pança eram representações de tipos genéricos da vida espanhola da época de Cervantes, o camponês e o fidalgote arruinado.

Ainda assim, poderíamos insistir: onde encontrar referenciais 'reais' para as pinturas abstratas de Wassily Kandinsky, os poemas dadaístas de Tristan Tzara, as imagens surrealistas de Luis Buñuel ou textos como os do escritor de horror H.P. Lovecraft, que descreve um de seus personagens como inumeráveis esferas que se encaixam perfeitamente uma na outra?

A partir da obra de Ian Watt (A ascensão do romance, 1957), a ordem da mímesis se inverteu e a 'fonte' da representação mimética passou a ser claramente indicada na figura do autor. As personagens da arte não são mais representações de caracteres reais, e sim tipos mentais pré-existentes que o escritor recupera. Assim, "um escritor de ficção descreve, estuda, apresenta personagens fictícios do mesmo modo como um historiador faz com personalidades históricas. [...] o escritor de ficção é um historiador dos reinos ficcionais" (DOLEŽEL, 1988, p. 479).

O crítico tcheco Lubomír Doležel, no entanto, não se satisfaz com tal explicação e esclarece que o processo mimético não se dá por mimetizações de 'mundos reais', mas de uma infinidade de 'mundos possíveis' (existentes, suponho, na mente dos autores), que, no entanto, são acessíveis apenas a partir do mundo 'real' (cf. DOLEŽEL, 1988, p. 485). No fim da análise, a arte continua sendo uma mímesis da realidade, embora se trate de uma realidade transformada pela interferência de um 'mundo possível' (i.e., mental). A escrita deixou de ser uma mímesis direta do mundo em que vivemos para voltar a ser uma mímesis de segunda ordem, como em Platão.

\section{Representação}

Até agora, vim empregando os termos mímesis e representação de maneira intercambiável, entendendo um como tradução do outro. Devemos observar, no entanto, que a mímesis é apenas um modo específico de representação (cf. COSTA LIMA, 2000, p. 230) e que o termo 'representação' tem uma história própria.

Oficina do Historiador, Porto Alegre, EDIPUCRS, v. 8, n. 1, jan./jun. 2015, p. 99-116. 
Na historiografia, especialmente entre os praticantes da chamada 'História cultural', o conceito de representação tem ocupado um lugar central. Segundo Sandra Jatahy Pesavento (2008, p. 40), “a representação não é uma cópia do real, sua imagem perfeita, espécie de reflexo, mas uma construção feita a partir dele":

Construídas sobre o mundo não só se colocam no lugar deste mundo, como fazem com que os homens percebam a realidade e pautem a sua existência. São matrizes geradoras de condutas e práticas sociais, dotadas de força integradora e coerciva, bem como explicativa do real. Indivíduos e grupos dão sentido ao mundo por meio das representações que constroem sobre a realidade.

(PESAVENTO, 2008, p. 39)

A historiadora brasileira afirma que "a proposta da História Cultural seria, pois, decifrar a realidade do passado por meio das suas representações, tentando chegar àquelas formas, discursivas e imagéticas, pelas quais os homens expressam a si próprios e o mundo" (PESAVENTO, 2008, p. 42). Nota-se, portanto, uma ambição explícita de se alcançar a realidade por meio das representações da mesma.

Ora, de certa maneira, essa sempre foi uma ambição da História como um todo, pois todas as fontes são, segundo as teorias miméticas, representações criadas pelos homens e, portanto, a única forma possível de se "decifrar a realidade do passado" é por meio das representações - não há outro meio. Dessa maneira, a proposta da História Cultural seria a proposta de toda a historiografia.

Contudo não podemos esquecer que já faz algum tempo que a História abandonou a pretensão de alcançar a "realidade por trás das fontes", tendo sido essa uma das principais críticas feitas pelos annalistes ao que eles chamaram de historiografia 'positivista'. Até mesmo Roger Chartier (1991, p. 182-183), que, segundo Pesavento, foi o principal divulgador do conceito de representação entre os historiadores, afirma que sua abordagem do conceito está mais próxima da noção sociológica de 'representações coletivas' (ou 'representações sociais'), normalmente definidas como produto de uma imensa cooperação entre os homens que se estende no tempo e no espaço e que não podem ser legitimamente reduzidas a algo como o conjunto das representações individuais, do que de qualquer ideia de apropriação da realidade.

Com essa perspectiva, por meio do conceito de representação o historiador deve buscar compreender como as práticas sociais de leitura construíram diferentes visões de

Oficina do Historiador, Porto Alegre, EDIPUCRS, v. 8, n. 1, jan./jun. 2015, p. 99-116. 
realidades sociais e qual o estatuto social dos conflitos entre diferentes leituras. Segundo Chartier (1991, p. 182), sua posição se colocava contra a antiga ideia hermenêutica de que um texto "existe em si, separado de toda materialidade". Trata-se, portanto, de um uso muito mais restrito do que aquele apregoado pela historiadora brasileira.

Temos, portanto, de dar um passo atrás e recuarmos no tempo para tentarmos entender o que a noção de 'representação' significava antes de sua apropriação pela historiografia. Na tradição filosófica, desde Kant pelo menos, a palavra foi utilizada como um termo comum que podia referir-se a todos os atos cognitivos - englobando percepção, sensação, conhecimento, intuição, conceito, noção e ideia. É, portanto, bastante difícil definir um conceito filosófico geral de representação sem referência a seu uso particular por um autor específico (cf. VOIGT, 2011, p.2), o que está além dos objetivos deste texto.

O conceito, no entanto, é fundamental no corpo da metapsicologia e aparece nos trabalhos teóricos de Sigmund Freud desde os seus primórdios. De fato, uma 'teoria da representação' é esboçada já em 1891, em um texto sobre afasias, no qual o médico austríaco descreve um aparelho de linguagem e introduz a distinção entre representação de objeto (Objektvorstellung) e representação de palavra (Wortvorstellung). Ambas são representações complexas, incluindo elementos visuais, acústicos e cenestésicos (a representação de objeto também pode incluir elementos táteis, olfativos, etc.) e formadas a partir de associações entre esses elementos (cf. MACEDOet al., 2008, p. 71-72).Essa noção freudiana de representação é precisamente aquilo que Paul Ricœur posteriormente chamou de mímesis I (2010, p. 82), ou seja, as imagens mentais formadas a partir de associações intelectuais entre distintas percepções sensórias.

Nesse modelo freudiano, as representações podem ser mapeadas à linguagem, pois a palavra corresponde a uma associação entre representações e sua significação se dá pela articulação entre a Wortvorstellung e a Objektvorstellung. Porém, em Freud, há uma dicotomia entre representação (Vorstellung) e pensamento (Gedanke), que é entendido como o 'processamento' das representações. Da mesma forma que os processos perceptivos fornecem o conteúdo representacional dos processos mentais, a experiência do sujeito fornece seu processamento. Assim, uma coisa são as relações associativas presentes nas representações, advindas das relações captadas pelos processos perceptivos, que formamos complexos de sensações associados em uma representação; outra coisa é a ativação ou a inibição desses complexos representacionais pela energia fluente no sistema nervoso. A esse

Oficina do Historiador, Porto Alegre, EDIPUCRS, v. 8, n. 1, jan./jun. 2015, p. 99-116. 
processamento de ativação ou inibição das representações Freud chama 'processo de pensamento' (cf. THÁ, 2004, p. 111-112).

É apenas a partir dessa distinção que podemos compreender o alcance da transformação entre aquilo que Paul Ricœur chama mímesis I e mímesis II (2010, p. 82). Essa segunda forma da mímesis é aquela estudada por Aristóteles, que procede à fabricação do produto-arte, ou seja, a própria criação poética. Acompanhemos: a) o mundo exterior é captado por nossos sentidos; b) nossa mente recebe os 'dados brutos' dos sentidos e os associa em representações mentais (mímesis I); c) nosso $\mathrm{Eu}$, influenciado por nossas experiências pessoais, inibe algumas dessas representações e ativa outras, formando nossas ideias; d) essas ideias são articuladas linguisticamente (mímesis II) na obra material. ${ }^{3}$

Não se pode esquecer que, além de todas as fases descritas acima, existe ainda uma mímesis III, que é a operação mental que ocorre no receptor da obra - seja ele ouvinte, espectador ou leitor (RICEUR, loc. cit.). Luiz Costa Lima (2000, p. 230) também chama a atenção para essa importante questão ao diferenciar entre uma representação 1, "uma construção humana equivalente a algo prévio a ela", e uma representação 2 ou representaçãoefeito, "aquela que se engendra no sujeito, à maneira de resposta afetiva ante fenômenos ou acontecimentos”. É interessante observar que o que Costa Lima chama de representaçãoefeito é o processo mental que ocorre tanto na mímesis I quanto na III.

\section{Linguagem e Narrativa}

Creio que não resta dúvida que nossas vidas estão assentadas na realidade, seja lá o que for que designemos por esse nome. Existimos em um mundo que independe da nossa existência para existir. Mas nossas experiências desse 'mundo real' estão sujeitas a poderosos 'filtros', mentais e sociais: nossos sentidos, desejos, vontades, pensamentos, a própria linguagem. $\mathrm{Na}$ verdade, esses filtros são tão poderosos que, efetivamente, desmontam a realidade externa e a recriam em uma forma que podemos compreender e na qual conseguimos viver. Ou seja, recriamos em nossa mente o mundo no qual existimos; ao comunicar nossas ideias a outrem, recriamos novamente o mundo mental no qual vivemos. A

\footnotetext{
${ }^{3}$ Segundo Freud, o pensamento é fundamentalmente não-verbal, portanto a articulação do pensamento e sua
} elaboração verbal seriam duas 'etapas' diferentes (ver THÁ, 2004, p. 113).

Oficina do Historiador, Porto Alegre, EDIPUCRS, v. 8, n. 1, jan./jun. 2015, p. 99-116. 
transformação operada pela mente e pela escrita, portanto, não é de ordem mimética, e sim criativa. Umberto Eco, por exemplo, afirma (2003, p. 219) que, desde Vico e sua Ciência Nova (1725), não se pode descrever o fenômeno poético "como desvio da norma existente", pois "a linguagem inteira" está fundamentada em um princípio de "criatividade estética".

Obviamente que esta não é uma ideia nova. Já na Antiguidade grega, o sofista Górgias afirmava que não existia nenhuma relação mimética e hierárquica entre a realidade externa e a palavra que falamos: "tal como o que é visível não pode se tornar audível e vice-versa, também o Ser, porque existe exteriormente, não pode se transformar na palavra" (Sexto Empírico, Contra os matemáticos, VII, 84). Segundo a teoria sofística da linguagem

Não é um objeto preexistente que é eficaz através da palavra, é a palavra que produz imediatamente algo como um objeto: sentimento, opinião, crença nessa ou naquela realidade, estado do mundo, a realidade mesma, indiscernivelmente. (CASSIN, 2005, p. 56)

De fato, os sentidos não nos fornecem dados organizados. A realidade - o "Ser externo", como a chama Górgias - não é linguística. Porém, ao recebermos essa massa informe de dados, nosso cérebro a organiza e o faz por meio da linguagem.

A multiplicidade das línguas revela a relatividade da realidade externa. Percebemos o mundo exterior de forma diferente, dependendo da língua na qual fomos 'treinados' para o perceber. Assim, Parmênides - e, depois dele, Platão, Aristóteles e uma longa tradição metafísica - utiliza-se de uma característica da língua grega de permitir a substantivação do verbo e cria a noção de Ser. Da mesma forma, Kant utiliza as categorias da língua alemã para analisar o mundo e pretende, assim, ter descoberto categorias universais do conhecimento. A questão é bem resumida pelo filósofo tcheco-brasileiro Vilém Flusser (2007, p. 52-53):

a realidade, este conjunto de dados brutos, está lá, dada e brutal, próxima do intelecto, mas inatingível. Este, o intelecto, dispõe de uma coleção de óculos, das diversas línguas, para observá-la. Toda vez que troca de óculos, a realidade 'parece ser' diferente. A dificuldade dessa imagem reside na expressão 'parece ser'. Para ser, a realidade precisa parecer. Portanto, toda vez que o intelecto troca de língua, a realidade é diferente. Mas uma ontologia que opera com uma infinidade de sistemas de realidade substituíveis é intolerável. É preferível abandonar o conceito da realidade como conjunto de dados brutos. É preferível dizer que os dados brutos se realizam somente quando articulados em palavras. Não são realidade, mas potencialidade. A realidade será, em consequência, o conjunto das línguas.

Oficina do Historiador, Porto Alegre, EDIPUCRS, v. 8, n. 1, jan./jun. 2015, p. 99-116. 
Ou seja, vivemos em um mundo linguístico, como o poeta Eurípides já percebera há dois mil e quinhentos anos: "Se a mesma coisa fosse para todos os homens, por natureza, bela e sábia, não haveria disputas ou discussões entre nós. Mas não há consistência ou imparcialidade quando se trata de mortais: tudo são nomes, sem realidade" (As fenícias, vv. 499-501).

Da mesma forma que nossa mente organiza, classifica, hierarquiza e dá sentido linguisticamente à massa de dados brutos que uma ontologia tradicional chamaria de 'realidade', a narrativa é a organização, classificação, hierarquização e significação linguística que damos aos acontecimentos históricos. Nas palavras de Arthur Danto, "qualquer narrativa é uma estrutura imposta sobre eventos, agrupando alguns deles com outros e descartando alguns mais carentes de relevância" (2007, p. 132). Ou seja, os eventos históricos são 'dados brutos', descontínuos, caóticos; é a pena do historiador que os vincula, os arranja e os dispõe de forma a criar uma explicação, que aplica relações de causa e efeito entre eles, que lhes dá sentido, enfim.

Com efeito, o campo da história é amplo e, mesmo se o limitarmos apenas aos eventos que 'realmente ocorreram' (como, de fato, o limitamos), inúmeros itinerários podem ser traçados entre um evento e outro (cf. RICEUR, 2010, p. 284). Exemplifiquemos com a questão temporal. Desde a Odisseia, com seu início in media res e seu extenso flashback onde o protagonista nos relata pessoalmente suas aventuras, os textos se recusam a seguir uma ordem cronológica 'natural', i.e., similar àquela dos acontecimentos. $\mathrm{Na}$ verdade, a "nãolinearidade é a norma ao invés da exceção em relatos narrativos” (GENETTE, 1990, p. 758).

Em uma narrativa, encontramos dois tipos de temporalidade: uma sucessão discreta de acontecimentos que seguimos ao longo da história (sempre podemos perguntar: "e depois, o que aconteceu?", mesmo se a narrativa vai e vem no tempo) e uma integração de todos os eventos contados em uma culminação, um encerramento, um clímax que configura a narrativa e nos ajuda a dar sentido a ela (cf. RICEEUR, 2008, p. 199). A operação narrativa é essa transformação de uma sucessão em uma configuração, de uma heterogeneidade temporal em uma homogeneidade significante. As narrativas recortam, reorganizam e transformam o tempo da natureza em um tempo que faz sentido para nós. Nas palavras de Paul Ricœur, “o tempo se torna tempo humano [apenas] na medida em que está articulado de maneira narrativa" (2010, p. 9).

Segundo Danto, a própria explicação histórica nada mais é do que "o preenchimento do meio entre os pontos de extremidade temporais de uma mudança” (2007, p. 233). Ou seja,

Oficina do Historiador, Porto Alegre, EDIPUCRS, v. 8, n. 1, jan./jun. 2015, p. 99-116. 
toma-se um ponto $\mathrm{x}$, no qual determinada situação se apresenta, e um ponto $\mathrm{y}$, posterior $\mathrm{a}$, no qual a situação se modificou. A explicação é a tentativa de preencher esse vazio entre os dois acontecimentos, de conectá-los narrativamente para que possamos entender como, a partir de um evento x, produziu-se um evento y. Nas palavras de Roland Barthes:

No discurso histórico da nossa civilização, o processo de significação visa sempre a 'preencher' o sentido da História: o historiador é aquele que reúne menos fatos do que significantes e os relata, quer dizer, organiza-os com a finalidade de estabelecer um sentido positivo e de preencher o vazio da série pura. (BARTHES, 2004, p. 176)

\section{O Romance e a Verdade}

Em 2008, quando eu era coordenador do curso de História no campus de Formosa da Universidade Estadual de Goiás, sugeri debatermos o filme Peixe Grande em um evento realizado conjuntamente por docentes de literatura e história. $\mathrm{O}$ evento, que acabou não sendo realizado, me levou a ler o livro Peixe grande: uma fábula do amor entre pai e filho, do escritor americano Daniel Wallace (2008) - título original: Big fish, a novel of mythic proportions (1998) -, no qual havia sido baseado o roteiro do filme dirigido por Tim Burton.

Embora a história seja similar - Will sente-se abandonado pelo pai, que passou boa parte da vida viajando, e quer conhecê-lo, mas, mesmo perto da morte, Edward continua rebatendo suas dúvidas com as mesmas piadas e histórias incríveis - o romance é muito mais ambíguo em relação à verdade, pois tudo é narrado em primeira pessoa por William Bloom: tanto as histórias que seu pai contava quanto os diálogos travados entre pai e filho aos pés do leito de morte do primeiro.

Assim, não podemos deixar de pensar que William pode ser o verdadeiro mentiroso e está simplesmente inventando tudo. O penúltimo capítulo do livro, por exemplo, começa com essas palavras: "Então, finalmente, aconteceu assim. Interrompa-me se já tiver ouvido essa" (WALLACE, 2008, p. 169; 2008, p. 170; grifos meus). Ao mesmo tempo que a verdade factual é marcada pelo verbo acontecer, a ficcionalidade do que será contado é destacada pela frase tradicional dos contadores de piadas. Em qual dos dois registros devemos acreditar? Trata-se do último diálogo ao pé do leito de morte de Edward (são quatro, no total) e o moribundo faz um pedido:

Oficina do Historiador, Porto Alegre, EDIPUCRS, v. 8, n. 1, jan./jun. 2015, p. 99-116. 
- Tudo bem, pode dizer. Diga-me antes que eu morra. Diga-me o que foi que eu ensinei para você. Diga-me tudo o que eu ensinei a você sobre a vida, para que eu possa morrer e não tenha que me preocupar tanto. Vá em frente... Diga. (WALLACE, 1998, p. 174; 2008, p. 175)

William, desejando ainda saber mais fatos sobre seu pai, desejando ardentemente conhecê-lo em seus próprios termos, conta-lhe a piada mais engraçada que seu pai já lhe apresentara, pois as histórias eram a lição de vida que ele lhe deixava. Aliviado, no último capítulo Edward escapa do hospital com seu filho e o livro se encerra com Will nos contando a verdadeira história da morte do pai, na qual ele se transforma em um peixe de proporções míticas e se torna fonte de novas histórias de pescador nas quais ninguém acredita.

Fim. The end. Não há corpo; não há enterro; não há convidados; não há a intromissão de uma 'realidade externa' que possa regular nossa crença nas histórias. Não há final epistemologicamente feliz. No romance, somos deixados diante de uma única opção: acreditarmos nas histórias contadas por William, pois elas são a única realidade.

Como historiadores, estamos, portanto, na mesma situação que o personagem William Bloom. ${ }^{4}$ Fazemos perguntas para o mundo, queremos conhecer o passado e tudo o que ele nos conta são histórias. Como podemos escapar dessa armadilha narrativa? Como encontrar alguma 'realidade histórica' por trás dos relatos, se estes a modificaram em todas as instâncias cognitivas entre a percepção do mundo e o ponto final da obra? Em minha opinião, temos que aprender com o narrador de Big fish e, simplesmente, aceitar que a humanidade é uma contadora de histórias. A verdade está nas narrativas e não no mundo.

Já em Aristóteles a função da poesia era propor à imaginação e à razão situações hipotéticas que constituíam experiências de pensamento, diante das quais poderíamos aprender a pensar sobre o aspecto ético da conduta humana (cf. RICCEUR, 2008, p. 200). A poesia, portanto, é uma maneira de compreendermos aquilo que não podemos experimentar, porque a vida não é fonte suficiente de experiências para a maior parte das pessoas. "Para compreender a complexidade do mundo e dizê-la, precisamos de mais, precisamos de romances, contos, imagens, músicas, filmes...” (OLIVEIRA\& GERALDI, 2010, p. 20).

\footnotetext{
${ }^{4}$ No romance, deve-se fazer uma distinção entre o personagem William Bloom e o narrador William Bloom. Enquanto o primeiro age procurando descobrir os fatos sobre seu pai, o segundo nos conta histórias sobre si mesmo e seu pai que, como já discutimos, podem ser inventadas porém não temos escolha a não ser acreditar (podemos, também, fechar o livro e desistir da ficção). No filme, tal distinção não existe, pois quase todas as histórias são narradas diretamente por Edward. Apenas uma vez, um dos personagens das histórias paternas que Will acreditava fictício conta a ele uma das histórias que seu pai havia lhe contado, dando, assim, valor de realidade ao que ele supunha ser mentira.
}

Oficina do Historiador, Porto Alegre, EDIPUCRS, v. 8, n. 1, jan./jun. 2015, p. 99-116. 
Precisamos de narrativas que nos supram as experiências que não vivemos. É por isso que o Egito helenístico, a Idade Média ou a pré-história brasileira nos interessam. Não por qualquer tipo de explicação que possam fornecer sobre o mundo de hoje, e sim por seu repertório de experiências que não vivemos e não poderemos nunca viver.

Além disso, a narrativa ocupa um lugar fundamental na compreensão que podemos ter de nossa própria vida. É em grande parte por meio das histórias que ouvimos e contamos que interpretamos e damos sentido a ela. De fato, "nossa familiaridade com a rede conceitual do agir humano é da mesma ordem da familiaridade que temos com os enredos das histórias que nos são conhecidas" (RICCEUR, 2008, p. 206). São as narrativas que ouvimos que nos fornecem os conceitos que usamos para analisar as situações apresentadas pela vida. Pode-se então dizer: as histórias são responsáveis pelo homem. Nas palavras de um dos personagens da vida de Edward Bloom:

- Está vendo - o velho disse. - Nós todos temos histórias, assim como você. As diversas formas com que ele nos tocou, nos ajudou, nos deu empregos, nos emprestou dinheiro, nos vendeu por atacado. Montes de histórias, grandes e pequenas. Todas elas se somam. No fim da vida, tudo se soma. É por isso que estamos aqui, William. Nós somos parte dele, de quem ele é, assim como ele é parte de nós. (WALLACE, 1998, p. 139; 2008, p. 141)

A historiografia é narrativa. Não porque seu 'formato' é narrativo, não porque a História seja uma 'espécie' de literatura ou um 'gênero' literário. Porque a narrativa é uma parte fundamental de nossas experiências, um aspecto fundamental da vida humana, aquilo que, no fim das contas, é o objeto e o objetivo de toda História.

\section{REFERÊNCIAS BIBLIOGRÁFICAS}

AUGUST, John. Big fish: the shooting script. Nova Iorque: Newmarket, 2004.

; BURTON, Tim. Big fish. [Filme]. Direção de Tim Burton; roteiro de John August. Estados Unidos: Columbia Pictures, 2003. DVD/Blu-ray disc, 125 min. color. BARTHES, Roland. O rumor da língua. Tradução de Mario Laranjeira. $2^{a}$ ed., São Paulo: Martins Fontes, 2004. Publicado originalmente em 1984.

BRANDÃO, Jacyntho Lins (1996). Narrativa e mimese no romance grego: o narrador, o narrado e a narração num gênero pós-antigo. Tese apresentada em concurso para o cargo de Professor Titular de Língua e Literatura Grega junto ao Departamento de Letras Clássicas da Faculdade de Letras da Universidade Federal de Minas Gerais.

Oficina do Historiador, Porto Alegre, EDIPUCRS, v. 8, n. 1, jan./jun. 2015, p. 99-116. 
CASSIN, Barbara. O efeito sofístico: sofística, filosofia, retórica, literatura. Tradução de Ana Lúcia de Oliveira, Maria Cristina Franco Ferraz \& Paulo Pinheiro. São Paulo: Ed. 34, 2005. Publicado originalmente em 1995.

CHARTIER, Roger. O mundo como representação. Estudos avançados (São Paulo: USP), vol. 5, num. 11, jan./abr. 1991. Disponível em <http://www.scielo.br/scielo.php? pid=S010340141991000100010\&script=sci_arttext $>$. Acesso em 20 jul. 2011.

COSTA LIMA, Luiz. Clio em questão: a narrativa na escrita da história. In: RIEDEL, Dierce Côrtes (org.). Narrativa: ficção \& história. Rio de Janeiro: Imago, 1988, p. 63-89.

Brasileira, 2000.

Mímesis: desafio ao pensamento. Rio de Janeiro: Civilização

DANTO, Arthur C. Narration and knowledge (including the integral text of Analytical philosophy of history'). Nova Iorque: Columbia University Press, 2007. Publicados originalmente em 1965 e 1985.

DOLEŽEL, Lubomír. Mimesis and possible worlds. Poetics today, Durham, NC, vol. 9, num. 3, 1988, p. 475-496.

ECO, Umberto. Sobre a literatura: ensaios. Tradução de Eliane Aguiar. Rio de Janeiro: Record, 2003. Publicado originalmente em 2002.

FLUSSER, Vilém. Língua e realidade. $3^{\mathrm{a}}$ ed., São Paulo: Annablume, 2007. Publicado originalmente em 1963.

GENETTE, Gérard. Fictional narrative, factual narrative. Poetics today (Durham, NC: Duke University Press), vol. 11, num. 4: Narratology revisited II, 1990, p. 755-773.

JAUSS, Hans-Robert. Expérience historique et fiction. In: GADOFRE, Gilbert (dir). Certitudes et incertitudes de l'Histoire. Trois colloques sur l'Histoire de l'Institut collégial européen. Paris: P.U.F., 1987, p. 117-132.

MACEDO, Mônica Medeiros Kother; WERLANG, Blanca Susana Guevara; DOCKHORN, Carolina Neumann de Barros Falcão. Vorstellung: a questão da representabilidade. Psicologia: ciência e profissão (Brasília: Conselho Federal de Psicologia), vol. 28, num. 1, mar. 2008. Disponível em <http://pepsic.bvsalud.org/scielo.php?pid=S141498932008000100006\&script $=$ sci_arttext $>$. Acesso em 21 out. 2010.

OLIVEIRA, Inês Barbosa de\& GERALDI, João Wanderley. Narrativas: outros conhecimentos, outras formas de expressão. In: OLIVEIRA, Inês Barbosa de (org.). Narrativas: outros conhecimentos, outras formas de expressão. Petrópolis, RJ: DP et alii/Rio de Janeiro: FAPERJ, 2010, p. 13-28.

PESAVENTO, Sandra Jatahy. História \& história cultural. $2^{\mathrm{a}}$ ed., Belo Horizonte: Autêntica, 2008. Publicado originalmente em 2003.

POSTER, Mark. Manifesto for a history of the media. In: JENKIS, Keith; MORGAN, Sue \& MUNSLOW, Alan (eds.). Manifestos for History. Londres/Nova Iorque: Routledge, 2007, p. $39-49$.

RICEUR, Paul. A memória, a história, o esquecimento. Tradução de Alan François et alli. Campinas, SP: Ed. UNICAMP, 2007. Publicado originalmente em 2000.

. Escritos e conferências 1 - em torno da psicanálise. Textos reunidos

e preparados por Catherine Goldenstein e Jean-Louis Schlegel, com a cooperação de Mireille Delbraccio; tradução de Edson Bini. São Paulo: Loyola, 2010. Publicado originalmente em 2008.

. Tempo e narrativa. 3 vols. Tradução de Claudia Berliner. São Paulo: Martins Fontes, 2010. Publicado originalmente entre 1983 e 1991.

RYAN, Marie-Laure. Toward a definition of narrative. In: HERMAN, David (ed.). The Cambridge companion to narrative. Cambridge: Cambridge University Press, 2007, p. 22-35.

Oficina do Historiador, Porto Alegre, EDIPUCRS, v. 8, n. 1, jan./jun. 2015, p. 99-116. 
TATARKIEWICZ, Władysław. Historia de seis ideas. Arte, belleza, forma, creatividad, mímesis, experiencia estética. Tradução de Francisco Rodríguez Martín. $6^{\mathrm{a}}$ ed., Madri: Tecnos, 2001. Publicado originalmente em 1976.

THÁ, Fabio. Representação e pensamento na obra freudiana: preliminares para uma abordagem cognitiva. Ágora: estudos em teoria psicanalítica (Rio de Janeiro: UFRJ), vol. 7, num. 1, jan. 2004. Disponível em <http://www.scielo.br/scielo.php?pid=S1516$14982004000100007 \&$ script= sci_arttext $>$. Acesso em 3 dez. 2011.

VOIGT, André Fabiano. Ritmanálise e poético-análise em Gaston Bachelard: a palavra literária e a história. Anais do XXVI Simpósio Nacional de História (São Paulo: ANPUH), jul. 2011. Disponível em <http://www.snh2011.anpuh.org/resources/anais/14/1307708364_ARQUIVO_Ritmanaliseep oetico-analiseANPUH.pdf $>$. Acesso em 20 jun. 2012.

WALLACE, Daniel. Big fish - a novel of mythic proportions. Nova Iorque: Penguin, 1998. . Peixe grande: uma fábula do amor entre pai e filho. Tradução de Léa Viveiros de Castro. Rio de Janeiro: Rocco, 2008. Publicado originalmente em 1998.

WILSON, Barrie. Big Fish: understanding historical narrative. The journal of religion and popular culture (Saskatoon, Canadá: The University of Saskatchewan), vol. 18, 2008. Disponível em <http://www.usask.ca/relst/jrpc/art18-bigfish.html>. Acesso em 22 dez. 2009.

ARTIGO ENVIADO EM: 28/06/2014 ACEITO PARA PUBLICAÇÃO EM: 16/01/2015

Oficina do Historiador, Porto Alegre, EDIPUCRS, v. 8, n. 1, jan./jun. 2015, p. 99-116. 